\title{
Dinámica de uso de suelo y sitios prioritarios para la restauración forestal del Corredor Biológico Río Tibás, Costa Rica
}

\section{Dynamics of Soil Use and Priority Sites for Forest Restoration of the Biological Corridor Tibas River, Costa Rica}

\author{
Jossy Esteban Calvo-Villalobos ${ }^{1}$ \\ Tania Bermúdez-Rojas ${ }^{2}$ \\ Hannia Vega-Bolaños ${ }^{3}$ \\ Universidad Nacional, Costa Rica
}

\section{Resumen}

Se evaluaron elementos paisajísticos (uso de suelo, vías de acceso, pendientes y fragilidad ambiental) y tendencias de uso de suelo durante el periodo 2005-2016 en el área propuesta para el Corredor Biológico Río Tibás (CBRT). A partir de ellos, se aplicó una metodología de selección de sitios prioritarios (SP) para la restauración de cobertura vegetal, y se realizó un diagnóstico social para valorar la percepción y anuencia de sus respectivos propietarios. El CBRT posee una distribución casi equitativa entre el uso urbano, agropecuario y natural, con una concentración importante de cobertura boscosa en su zona alta. No obstante, en 11 años ha experimentado un proceso de urbanización hasta tres veces más acelerado que otras zonas de la región, siendo los usos agropecuarios los más vulnerables al cambio. La aplicación de la metodología delimitó 20 SP de manejo, de los cuales,

1 Lic. Escuela de Ciencias Biológicas, Universidad Nacional, Costa Rica. Correo electrónico: jcalvo2412@ gmail.com

2 M.Sc. Escuela de Ciencias Biológicas, Universidad Nacional, Costa Rica. Correo electrónico: tania. bermudez.rojas@una.cr

3 Licda. Escuela de Ciencias Biológicas, Universidad Nacional, Costa Rica. Correo electrónico: hannia.vega. bolanos@una.cr 
Jossy Esteban Calvo-Villalobos, Tania Bermúdez-Rojas, Hannia Vega-Bolaños. Dynamics of Soil Use and Priority Sites for Forest Restoration of the Biological Corridor Tibas River, Costa Rica

en 10 se realizó el diagnóstico social. El 94 \% de los propietarios están anuentes a la restauración, motivados, principalmente, por la conservación del agua, biodiversidad y paisaje.

Palabras clave: Cobertura, evaluación multicriterio, interurbano, Heredia, Costa Rica

\begin{abstract}
An evaluation was conducted on landscape elements (land use, access roads, slopes, and environmental fragility) and trends in the use of soil during the period 2005-2016 in the area proposed for the Biological Corridor Tibas River (CBRT). From these elements and trends, a methodology for the selection of priority sites (SP) was applied for the restoration of plant cover, and a survey to assess the perception and consent of their respective owners was applied. The CBRT has a distribution almost equitable between urban, agricultural and natural use, with an important concentration of forest cover in its high area. However, in 11 years the CBRT has undergone a process of urbanization, up to three times faster than other urban areas in the region, being the agricultural uses the most vulnerable to change. The implementation of the methodology identified 20 priority sites of management; the above-mentioned survey was applied in 10 of them. The $94 \%$ of the owners are willing to the restoration, motivated primarily by the conservation of water, biodiversity and landscape.
\end{abstract}

Keywords: Coverage, multicriteria evaluation, Intercity, Heredia, Costa Rica.

\title{
Introducción
}

Los cambios acelerados y desordenados en el uso del suelo en zonas aledañas a los ríos urbanos del Gran Área Metropolitana (GAM) de Costa Rica generan diversos impactos negativos en ecosistemas y comunidades (Leandro, Coto y Salgado 2010; Calvo y Mora 2012). En este contexto, la Compañía Nacional de Fuerza y Luz (CNFL), una empresa dedicada a la venta y distribución de electricidad en este país, en conjunto con instituciones gubernamentales y municipalidades de la GAM, propone la implementación de corredores biológicos interurbanos como elemento base para la recuperación de conectividad y servicios ecosistémicos de la región (Feoli, 2013).

En este sentido, los ríos urbanos constituyen enlaces naturales remanentes, casi lineales a través del paisaje, que si se fortalecen son ideales para proporcionar conectividad entre hábitats para muchas especies y mantener beneficios como la conservación del agua y los suelos, entre otros (Sanderson et al., 2003). Uno de los corredores propuestos es el Corredor Biológico Río Tibás (CBRT), un sistema hidrológico que, actualmente, constituye una de las zonas de recarga acuífera más importantes para el abastecimiento de agua para la población en el Valle Central de Costa Rica (Ramírez, 2007). 
Dicho corredor pretende integrar áreas naturales, públicas, privadas, rurales y urbanas, tomando como base el "enfoque ecosistémico" de concertación social y uso sostenible de la biodiversidad en esos territorios (Andrade, 2007). Esta investigación se realiza como insumo para su implementación y, su objetivo principal es delimitar sitios prioritarios para la restauración de la cobertura vegetal. Para ello, se evaluaron elementos biofísicos en el área del corredor y se aplicó una metodología modificada de la propuesta de Villalobos (2013) para la rehabilitación forestal del río Pirro, que se basa en la vulnerabilidad de los sitios al cambio de uso de suelo por urbanización.

\section{Área de estudio}

La ubicación del CBRT fue establecida por la CNFL y corresponde a un área de $300 \mathrm{~m}$, en ambos lados del río Tibás, entre las coordenadas $10^{\circ} 01.1091^{\prime}$ latitud Norte y $83^{\circ} 03.358^{\prime} O$ longitud Oeste. El río se extiende $19,5 \mathrm{~km}$ entre los 1000 y $2000 \mathrm{msnm}$ y se ubica en la parte alta de la subcuenca del río Virilla. Administrativamente tiene jurisdicción en 3 cantones; San Rafael, San Isidro y Santo Domingo de Heredia (Ortiz, 2014).

A nivel regional se considera una zona urbana y periurbana donde aún persisten actividades agropecuarias como el cultivo de café y ganadería. Para este estudio, el área de interés se estratificó en tres zonas, según las franjas altitudinales, definidos como zona alta (1530-2000 msnm), media (1190-1529 msnm) y baja (1000-1189 msnm) (Figura 1). Dicha zonificación fue elaborada por la CNFL con base en las características del cauce. 
Jossy Esteban Calvo-Villalobos, Tania Bermúdez-Rojas, Hannia Vega-Bolaños. Dynamics of Soil Use and Priority Sites for Forest Restoration of the Biological Corridor Tibas River, Costa Rica

Figura 1. Ubicación y zonificación altitudinal del Corredor Biológico Río Tibás, Heredia Costa Rica.
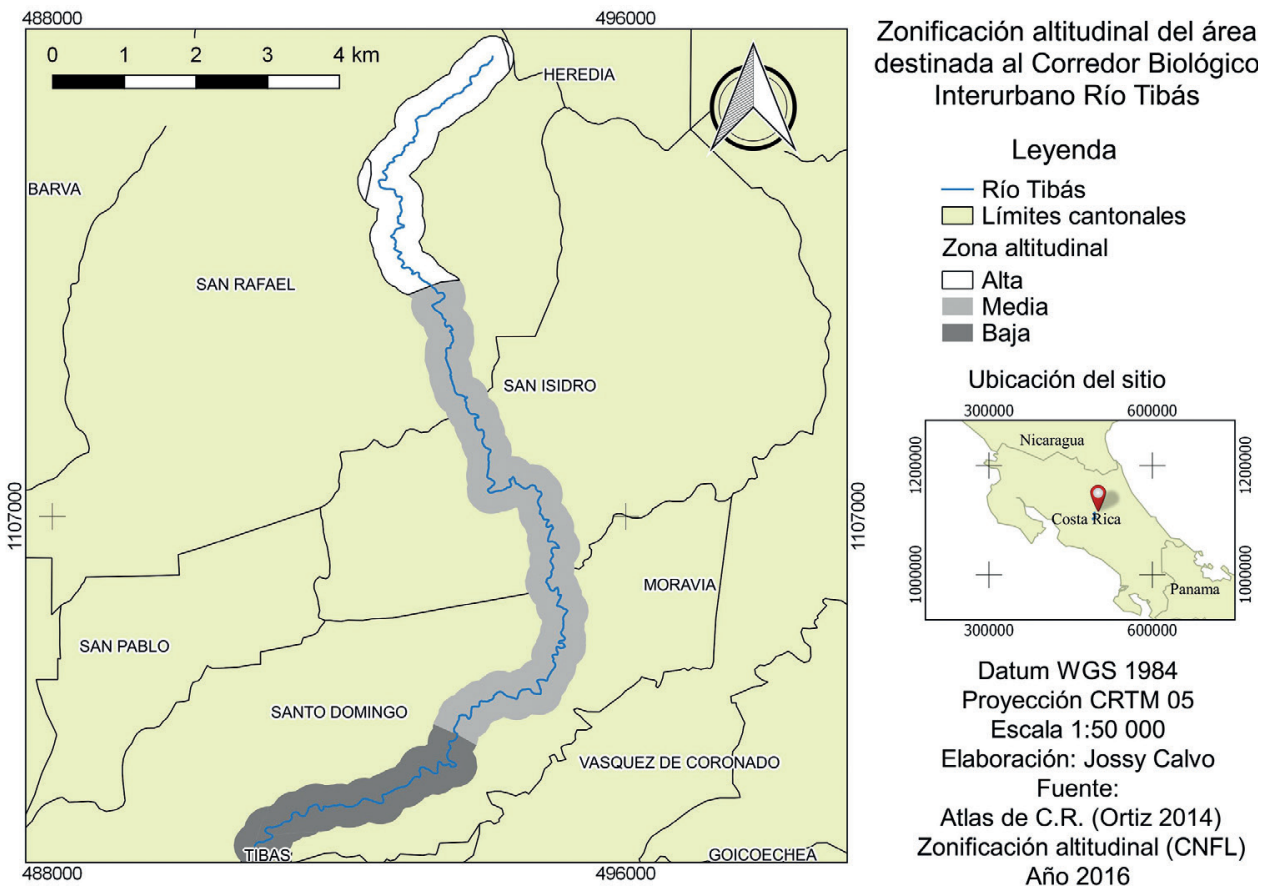

\section{Materiales y métodos}

\section{Clasificación de uso de suelo}

La investigación se realizó entre setiembre del 2015 y marzo del 2016. Se analizaron imágenes satelitales obtenidas de Google Earth y se clasificó la cobertura del suelo a partir del módulo "OpenLayers plugin" del software QGIS (versión 2.12 Lyon, 2009). Las clases de cobertura que se consideraron fueron: 1) agrícola, 2) agrícola arbolado, 3) boscoso, 4) infraestructura, 5) pastos, 6) pasto arbolado y 7) suelo desnudo.

Adicionalmente, se realizaron visitas de campo, con el fin de corroborar la información. Para ello, se visitaron 90 puntos en total, 30 en cada estrato, seleccionados de manera aleatoria. Luego se construyó una matriz de confusión entre el uso de suelo observado y el de la imagen satelital a partir del módulo "Accuracy assessment” de QGIS y el cálculo del índice 
de Kappa, como medida de precisión (Rosenfield y Fitzpatrick-Lins, 1986; Murty \& Tiwari, 2015).

\section{Cambio de uso del suelo y tendencias futuras al año 2025}

Se realizó un mapa de uso de suelo en la región para el año 2005, a partir de imágenes aéreas obtenidas del proyecto PRUGAM (2005), utilizando las mismas categorías anteriores. Este se contrastó con el mapa de uso actual y se evaluaron cambios de estructura del paisaje mediante el uso del módulo Patch Analysist del software Arcgis 3.3. Posteriormente, se realizó una proyección de uso de suelo al año 2025, a partir de un modelaje de Cadenas de Markov con el módulo Land Change Modeler, del software IDRISI (Paegelow, Olmedo y Toribio, 2003; Morera, Romero, Sandoval y Alfaro, 2013).

\section{Selección de sitios prioritarios para restauración}

Utilizando el software QGIS, se delimitó el sitio de estudio a través de cuadrículas de $5000 \mathrm{~m}^{2}$ cada una. Se identificaron y seleccionaron aquellas que correspondían a zonas que podían ser restauradas debido a la falta de cobertura vegetal: suelos desnudos, uso agropecuario o coberturas boscosas fragmentadas. Cada cuadrícula seleccionada corresponde a un sitio potencial.

En cada sitio potencial se sobrepusieron distintas capas de información, utilizando la matriz de "Criterios biofísicos y socioeconómicos para priorizar sitios de restauración de la cobertura vegetal en el CBRT" modificada de Villalobos (2103) (Cuadros 1 y 2). La matriz se basa en la asignación de valores a criterios biofísicos y sociales de los sitios, determinando zonas de mayor puntaje y prioritarias para la restauración. 
Jossy Esteban Calvo-Villalobos, Tania Bermúdez-Rojas, Hannia Vega-Bolaños. Dynamics of Soil Use and Priority Sites for Forest Restoration of the Biological Corridor Tibas River, Costa Rica

Cuadro 1. Criterios biofísicos y socioeconómicos para priorizar sitios de restauración de la cobertura vegetal en el CBRT

\begin{tabular}{|c|c|c|c|}
\hline Parámetro & $\begin{array}{l}\text { Valor } \\
(\%)\end{array}$ & $\begin{array}{c}\text { Valoración } \\
\text { de } 1 \text { a } 3\end{array}$ & Atributo \\
\hline \multirow[t]{3}{*}{ Fragilidad ambiental del sitio (IFA) } & \multirow[t]{3}{*}{25} & 3 & Muy alta \\
\hline & & 2 & Alta \\
\hline & & 1 & Media \\
\hline \multirow[t]{3}{*}{ Cobertura } & \multirow[t]{3}{*}{15} & 3 & Suelo desnudo \\
\hline & & 2 & Agropecuario \\
\hline & & 1 & Fragmentado \\
\hline \multirow[t]{3}{*}{ Pendiente } & \multirow[t]{3}{*}{15} & 3 & $\leq 29.9 \%$ \\
\hline & & 2 & $30 \%-59.9 \%$ \\
\hline & & 1 & $\geq 60 \%$ \\
\hline \multirow[t]{2}{*}{ Zonas protectoras de ríos y quebradas } & \multirow[t]{2}{*}{15} & 2 & Presencia \\
\hline & & 1 & Ausencia \\
\hline \multirow{3}{*}{$\begin{array}{l}\text { Probabilidad de conversión a un uso de } \\
\text { suelo menos favorable; a partir de modelaje } \\
\text { de Cadenas de Markov al año } 2025\end{array}$} & \multirow[t]{3}{*}{10} & 3 & $\geq 50 \%$ \\
\hline & & 2 & $15.1 \%-49.9 \%$ \\
\hline & & 1 & $\leq 15$ \\
\hline \multirow[t]{2}{*}{ Infraestructura en el sitio } & \multirow[t]{2}{*}{10} & 2 & Presencia \\
\hline & & 1 & Ausencia \\
\hline \multirow[t]{3}{*}{ Cercanía de vías de acceso al sitio } & \multirow[t]{3}{*}{10} & 3 & Sobre la zona \\
\hline & & 2 & A 5 metros del sitio \\
\hline & & 1 & A más de 5 metros \\
\hline
\end{tabular}

Modificado de Villalobos (2013) 
Jossy Esteban Calvo-Villalobos, Tania Bermúdez-Rojas, Hannia Vega-Bolaños. Dinámica de uso de suelo y sitios prioritarios para la restauración forestal del Corredor Biológico Río Tibás, Costa Rica

\section{Cuadro 2. Descripción de los criterios biofísicos y socioeconómicos para priorizar sitios de restauración de la cobertura vegetal en el CBRT}

\begin{tabular}{|c|c|c|}
\hline Parámetro & Justificación y criterio utilizado & Metodología \\
\hline $\begin{array}{l}\text { Fragilidad } \\
\text { ambiental del sitio; } \\
\text { mediante el Índice } \\
\text { de Fragilidad } \\
\text { Ambiental (IFA) }\end{array}$ & $\begin{array}{l}\text {-Se usó el IFA; una herramienta } \\
\text { integral que identifica terrenos con } \\
\text { limitaciones técnicas para el desarrollo, } \\
\text { así como sitios con potencial para la } \\
\text { conservación hídrica y terrestre, con base } \\
\text { en parámetros geológicos, edafológicos, } \\
\text { biológicos y antropogénicos (Campos y } \\
\text { Astorga, 2009). } \\
\text {-Sitios con mayor fragilidad ambiental } \\
\text { poseen mayor viabilidad técnica y legal } \\
\text { para ser restaurados. }\end{array}$ & $\begin{array}{l}\text { Se utilizaron mapas de IFA que } \\
\text { fueron realizados previamente } \\
\text { para el GAM otorgados por } \\
\text { la CNFL. Son prioritarios los } \\
\text { sitios ubicados en áreas que } \\
\text { presenten clase de nivel I o II } \\
\text { (fragilidad ambiental muy alta } \\
\text { o alta respectivamente). }\end{array}$ \\
\hline Cobertura & $\begin{array}{l}\text {-Suelos desnudos y/o con cobertura } \\
\text { vegetal escasa son más propensos a la } \\
\text { erosión que sitios con cobertura arbórea. }\end{array}$ & $\begin{array}{l}\text { A partir de los mapas realizados } \\
\text { de uso de suelo, son prioritarios } \\
\text { sitios con suelo desnudo o } \\
\text { cobertura vegetal escasa. }\end{array}$ \\
\hline Pendiente & $\begin{array}{l}\text {-Se relaciona con el grado de } \\
\text { vulnerabilidad al cambio de uso del suelo. } \\
\text {-Sitios con pendientes menores presentan } \\
\text { condiciones topográficas más aptas } \\
\text { para la construcción de infraestructuras } \\
\text { y otros usos no conformes en zonas } \\
\text { ambientalmente frágiles. }\end{array}$ & $\begin{array}{l}\text { Se desarrolló un modelo de } \\
\text { elevación digital y un mapa } \\
\text { de pendientes del sitio a } \\
\text { partir del trabajo de imágenes } \\
\text { Raster del sensor Aster. Sitios } \\
\text { con pendientes menores son } \\
\text { prioritarios. } \\
\text { La imagen Raster se obtuvo } \\
\text { de la página web del Servicio } \\
\text { Geológico de los Estados } \\
\text { Unidos (http://earthexplorer. } \\
\text { usgs.gov) }\end{array}$ \\
\hline $\begin{array}{l}\text { Zonas protectoras } \\
\text { de ríos y quebradas }\end{array}$ & $\begin{array}{l}\text {-La Ley Forestal de Costa Rica }\left(\mathrm{N}^{\circ}\right. \\
7575) \text { establece que las zonas de } \\
\text { protección del recurso hídrico deben } \\
\text { mantenerse bajo cobertura forestal. } \\
\text {-Estas se definen como una franja de } 10 \\
\text { metros en zonas urbanas y } 15 \text { metros en } \\
\text { zonas rurales medidas horizontalmente a } \\
\text { ambos lados de ríos, quebradas o arroyos, } \\
\text { si el terreno es plano, y de } 50 \text { metros si el } \\
\text { terreno es quebrado. }\end{array}$ & $\begin{array}{l}\text { Se realizó un mapa de zonas } \\
\text { protectoras a través del atlas } \\
\text { de ríos y quebradas de Costa } \\
\text { Rica (Ortiz 2014), - realizando } \\
\text { los ajustes necesarios con } \\
\text { imágenes satelitales y trabajo } \\
\text { de campo - y el modelo de } \\
\text { pendiente del punto anterior. } \\
\text { Sitios con presencia de zonas } \\
\text { protectoras son prioritarios. }\end{array}$ \\
\hline
\end{tabular}


Jossy Esteban Calvo-Villalobos, Tania Bermúdez-Rojas, Hannia Vega-Bolaños. Dynamics of Soil Use and Priority Sites for Forest Restoration of the Biological Corridor Tibas River, Costa Rica

\begin{tabular}{|c|c|c|}
\hline Parámetro & Justificación y criterio utilizado & Metodología \\
\hline $\begin{array}{l}\text { Probabilidad de } \\
\text { conversión a un } \\
\text { uso de suelo menos } \\
\text { favorable a partir } \\
\text { de modelaje de } \\
\text { Cadenas de Markov } \\
\text { al año } 2025\end{array}$ & $\begin{array}{l}\text {-El algoritmo de cadenas de Markov } \\
\text { compara dos mapas de ocupación de } \\
\text { suelo en un tiempo discreto, donde } \\
\text { el valor del tiempo } \mathrm{T}_{1} \text { depende de los } \\
\text { valores en los tiempos } \mathrm{T}_{0} \text { y } \mathrm{T}_{-1} \text { (Paegelow } \\
\text { et al., 2003). } \\
\text {-Este tipo de análisis estocásticos, } \\
\text { mediante el uso de software de modelaje } \\
\text { en SIG permiten analizar las tendencias } \\
\text { de cambio de uso del suelo y estimar } \\
\text { el riesgo de que ocurran procesos de } \\
\text { degradación de la cobertura vegetal en un } \\
\text { periodo y sitio determinado (Morera et } \\
\text { al., 2013). } \\
\text {-Según el modelaje realizado, sitios } \\
\text { que proyecten mayor probabilidad de } \\
\text { conversión a perturbaciones son más } \\
\text { vulnerables a la degradación, debido, por } \\
\text { ejemplo, a factores socioeconómicos que } \\
\text { ocurren en la zona. }\end{array}$ & $\begin{array}{l}\text { Según el modelaje, aquellos } \\
\text { sitios que proyecten mayor } \\
\text { probabilidad de conversión a } \\
\text { perturbaciones son prioritarios. } \\
\text { Incluyendo: } \\
\text {-Pérdida o degradación de la } \\
\text { cobertura vegetal. Por ejemplo, } \\
\text { conversión de cobertura } \\
\text { boscosa a uso agropecuario. } \\
\text {-Coberturas que limiten futuros } \\
\text { procesos de restauración. } \\
\text { Ejemplo, conversión de suelos } \\
\text { desnudos a residenciales y } \\
\text { otras edificaciones. }\end{array}$ \\
\hline $\begin{array}{l}\text { Infraestructura en } \\
\text { el sitio }\end{array}$ & $\begin{array}{l}\text {-La presencia de infraestructura en el } \\
\text { sitio se relaciona con mayor influencia } \\
\text { poblacional y vulnerabilidad a cambio de } \\
\text { uso de suelos. }\end{array}$ & $\begin{array}{l}\text { Se trabajó a partir del mapa } \\
\text { de uso de suelo para el } \\
\text { periodo 2016. Aquellos sitios } \\
\text { potenciales con presencia de } \\
\text { infraestructura son prioritarios. }\end{array}$ \\
\hline $\begin{array}{l}\text { Cercanía de vías de } \\
\text { acceso al sitio }\end{array}$ & $\begin{array}{l}\text { Las vías de acceso inciden en la facilidad } \\
\text { de ingreso a los sitios para la realización } \\
\text { de cambios de uso del suelo. Por otro } \\
\text { lado, facilitan el ingreso para realizar } \\
\text { estrategias de manejo. }\end{array}$ & $\begin{array}{l}\text { Se trabajó a partir del mapa } \\
\text { de uso de suelo elaborado } \\
\text { para el } 2016 \text {. Aquellos sitios } \\
\text { con mayor cercanía a vías de } \\
\text { acceso son prioritarios. }\end{array}$ \\
\hline
\end{tabular}

Fuente: Modificado de Villalobos (2013)

Finalmente, los sitios prioritarios son los que obtienen mayor puntaje en la matriz, utilizando la siguiente fórmula:

$$
\mathrm{VR}=\frac{\mathrm{Vi} \times \mathrm{Vp}}{\sum \mathrm{i}}
$$

Donde: VR Valor porcentual de la ponderación, $\mathrm{Vi}=$ valor del indicador (escala de 1 a 3 ), $\mathrm{Vp}$ = valor porcentual del parámetro y $\sum \mathrm{i}=$ sumatoria de los indicadores del parámetro. 
Diagnóstico social en los sitios definidos como prioritarios:

En los sitios prioritarios seleccionados se procedió a contactar a sus respectivos propietarios para valorar su percepción y anuencia hacia la restauración de la cobertura vegetal. La información de propiedades se obtuvo a través de mapas catastrales obtenidos en las municipalidades de San Rafael, San Isidro y Santo Domingo de Heredia, así como visitas de campo y consultas a vecinos.

\section{Resultados}

\section{Clasificación de uso de suelo}

La exactitud de clasificación del uso de suelo a partir de las imágenes satelitales, trabajo de campo y la aplicación del índice de Kappa variaron entre 0.81 y $0.86 \%$, lo que sugiere un ajuste óptimo de precisión (Rosenfield y Fitzpatrick-Lins, 1986; Murty y Tiwari, 2015). De acuerdo con la evaluación, la mayor parte del área del corredor está ocupada por cobertura boscosa que representó el $27 \%$ del total (288.7 ha). No obstante, el $58 \%$ de la misma se concentra en la zona alta, ya que en las zonas media y baja la cobertura boscosa solo ocupa un $15 \%$ y $17 \%$ de su área total, respectivamente (Figura 2). 
Jossy Esteban Calvo-Villalobos, Tania Bermúdez-Rojas, Hannia Vega-Bolaños. Dynamics of Soil Use and Priority Sites for Forest Restoration of the Biological Corridor Tibas River, Costa Rica

Figura 2. Uso del suelo en el área del Corredor Biológico Río Tibás, Heredia, Costa Rica, 2016.
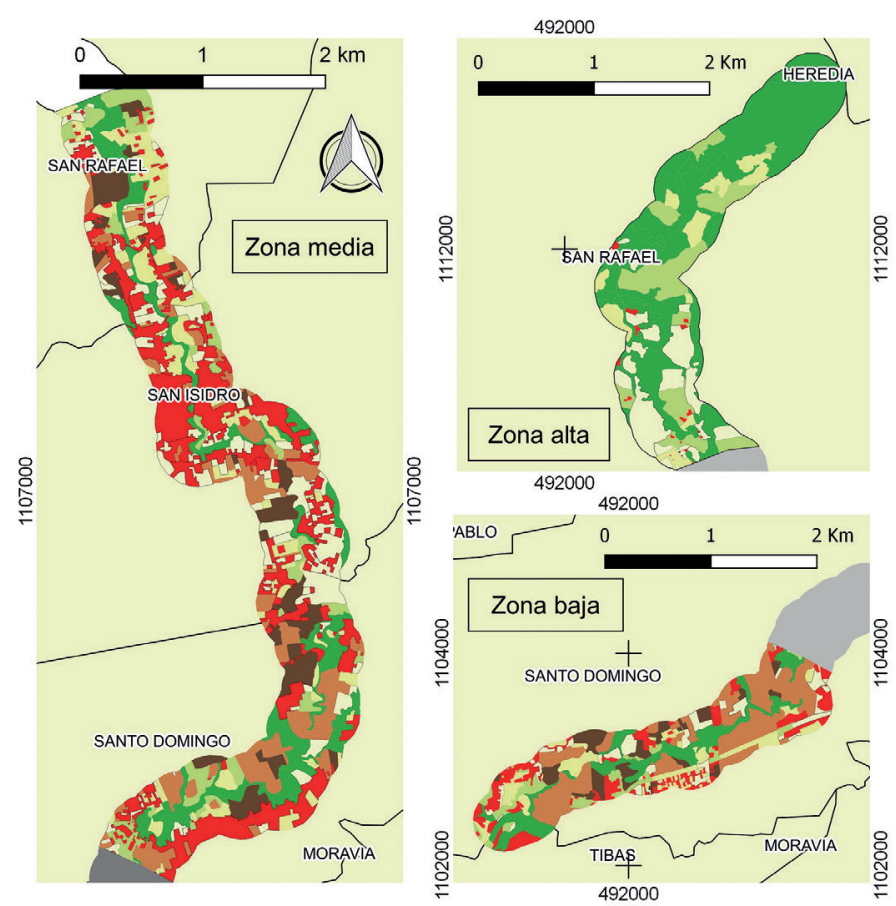

Uso del suelo en el Corredor Biológico Río Tibás

\section{Leyenda}

$\square$ Limites cantonales Uso de suelo

Agrícola (202.8 ha)

- Agrícola arbolado (101.2 ha)

Boscoso (280.7 ha)

- Infraestructura (138.7 ha)

Pasto (197.3 ha)

Pasto arbolado (106.7 ha)

Suelo desnudo (60.1 ha)

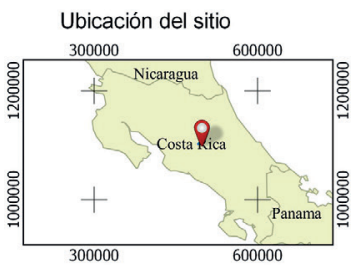

Datum WGS 1984 Proyección CRTM 05 Escala 1:50 000

Elaboración: Jossy Calvo Fuente:

Atlas de C.R. (Ortiz 2014)

Trabajo de campo (Calvo 2016) Año 2017

El segundo uso de suelo más abundante es el de infraestructura, que ocupa un $17 \%$ del área total del corredor y se distribuye, principalmente, en la zona media (79\%). Cabe resaltar que entre un 4 al $8 \%$ de las zonas protectoras del río se encuentran ocupadas por uso urbano. Por otro lado, en la zona baja el tipo de uso mayormente representado es el agrícola (principalmente café) que ocupó el $24 \%$. (Figura 2).

\section{Cambio de uso del suelo y tendencias futuras al año 2025}

Al contrastar los cambios de uso de suelo ocurridos entre el periodo 2005-2016, se encontró que el uso que representó mayor cambio fue el suelo desnudo, que incrementó un $10 \%$ su área de ocupación (92.5 ha). Este uso corresponde, principalmente, a tierras trabajadas destinadas a la creación de proyectos urbanísticos. Por otro lado, el uso agrícola, 
mayormente, compuesto por cafetales disminuyó 61.7 ha y el agrícola arbolado (cafetales con sombra) 18.9 ha (Figura 3 ).

Figura 3. Cambios en hectáreas del tipo de cobertura en el área del Corredor Biológico Río Tibás durante el periodo 2005-2016

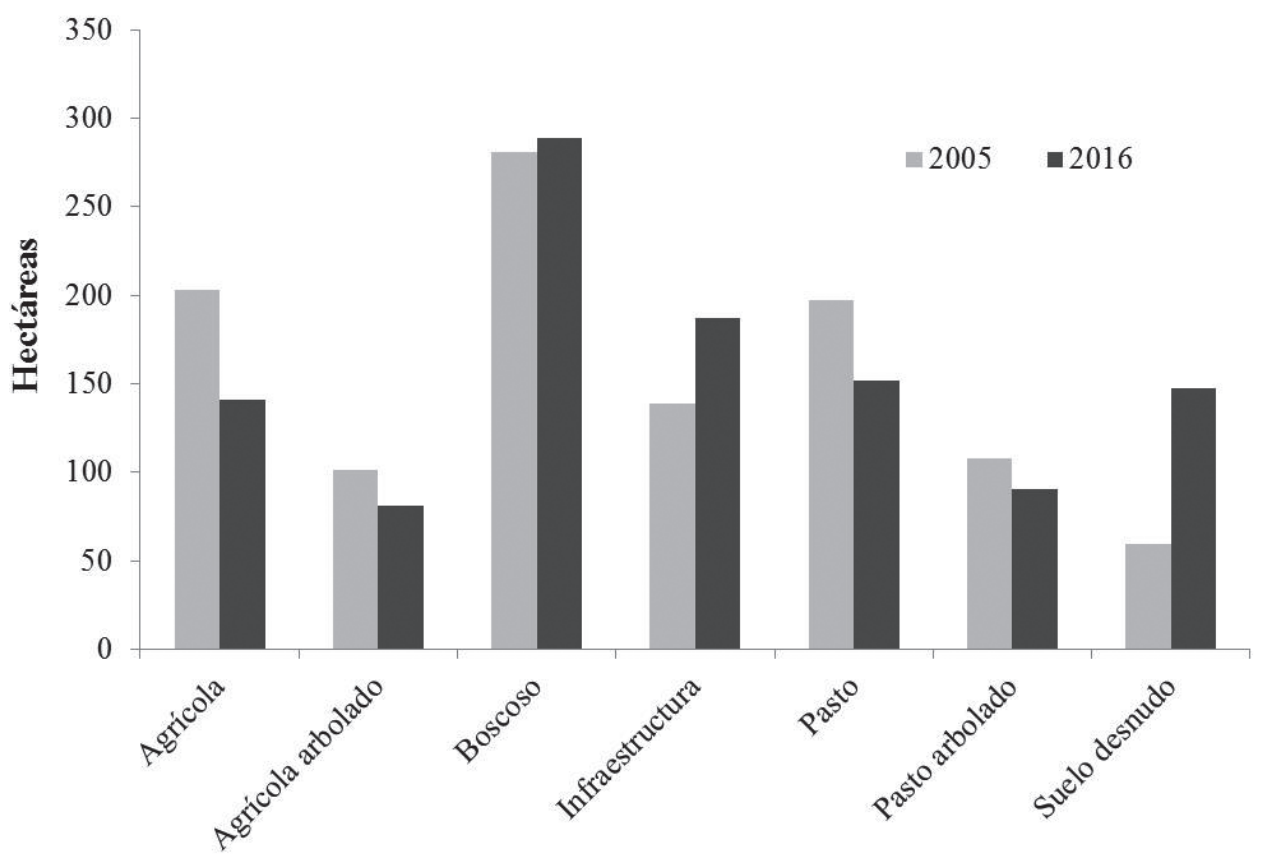

Fuente: Elaboración propia.

De acuerdo con el análisis de cadenas de Markov, los sitios que proyectan mayor probabilidad de cambio de uso que implicaría la pérdida de cobertura vegetal, se ubican en la zona alta; en los sectores más cercanos al centro del distrito de Concepción de San Rafael, así como varias regiones de la zona media (Figura 4). Por otro lado, de mantenerse la trayectoria de cambio actual las coberturas boscosas en todos los estratos, se proyectan altas probabilidades de conservarse al año 2025. Siendo usos de suelo como pastos y cafetales arbolados los que tienen probabilidades más altas de pérdida de cobertura vegetal. 
Jossy Esteban Calvo-Villalobos, Tania Bermúdez-Rojas, Hannia Vega-Bolaños. Dynamics of Soil Use and Priority Sites for Forest Restoration of the Biological Corridor Tibas River, Costa Rica

Figura 4. Probabilidad de cambio de uso del suelo que implique la pérdida de cobertura vegetal, en el Corredor Biológico Río Tibás al año 2025, a partir de la tendencia de cambio en el periodo 2005-2016 y modelaje de cadenas de Markov.
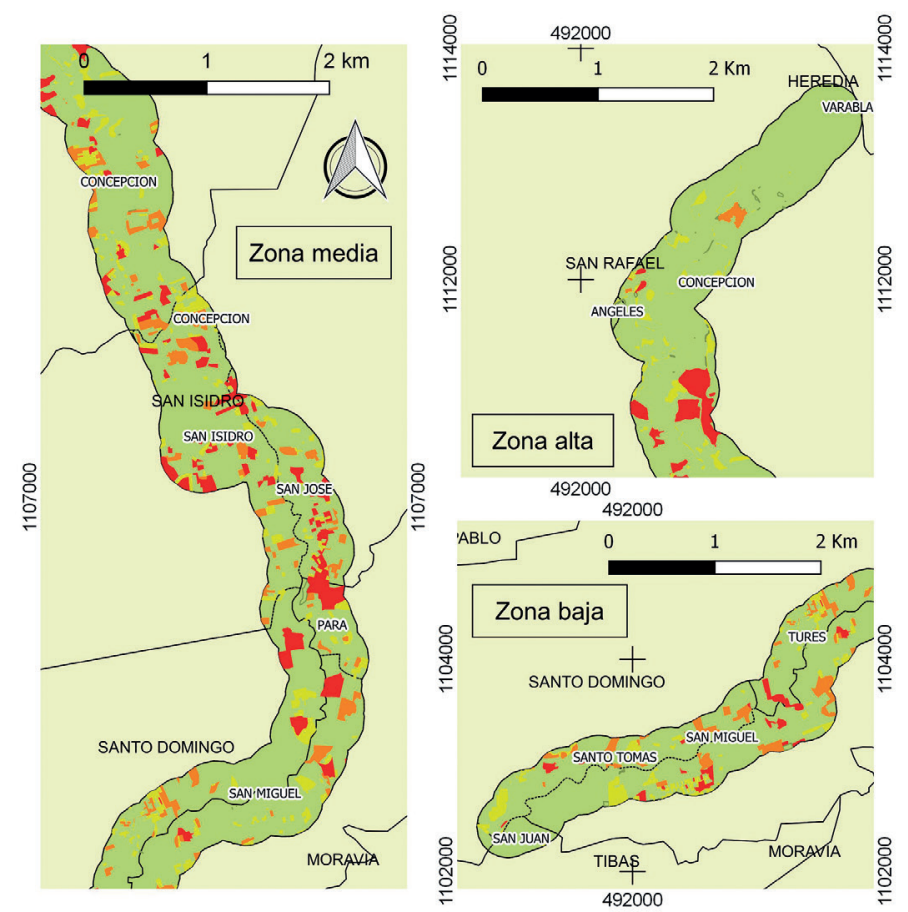

Probabilidad de pérdida de cobertura vegetal en el Corredor Biológico Río Tibás al año 2025

Leyenda

Límites cantonales Límites distritales

Proyección

$\square 0 \%$

$1-10 \%$

$11-25 \%$

Mayor a $26 \%$

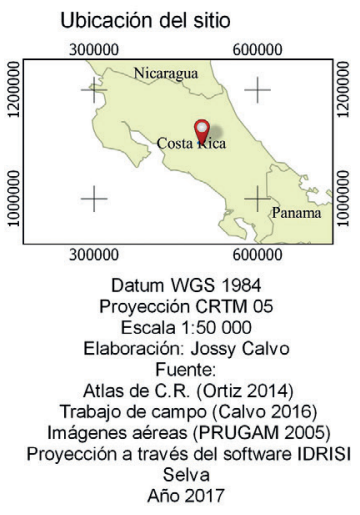

En la zona alta los pastos proyectaron una probabilidad de cambio con un máximo de $35 \%$ de pasar a ser suelos desnudos. Mientras que en los estratos medio y bajo la probabilidad de que el tipo de cobertura "agrícola arbolado" permanezca en el 2025 es de apenas el $30 \%$. Esto refleja la gran dinámica de estos sistemas, con altas probabilidades de cambio a coberturas agrícolas o suelos desnudos. También se resalta que la mayor probabilidad de urbanización se presenta en la zona media, proveniente, principalmente, de suelos desnudos (35\%), así como en el estrato bajo, donde los usos más vulnerables fueron los pastos (29\%) y agrícola arbolado (24\%) (Cuadro 3). 
Jossy Esteban Calvo-Villalobos, Tania Bermúdez-Rojas, Hannia Vega-Bolaños. Dinámica de uso de suelo y sitios prioritarios para la restauración forestal del Corredor Biológico Río Tibás, Costa Rica

Cuadro 3. Probabilidad de cambio de uso de suelo para el año 2025 en la región del CBRT, a partir de la tendencia de cambio en el periodo 20052016 y el modelaje de cadenas de Markov. NA* = No aplica debido a que la cobertura no estaba representada en el estrato. Se resaltan en color rojo los mayores porcentajes de probabilidad de cambio.

\begin{tabular}{|c|c|c|c|c|c|c|c|}
\hline \multicolumn{8}{|c|}{ Cambio al 2025} \\
\hline Clases & Agrícola & $\begin{array}{c}\text { Agrícola } \\
\text { arbolado }\end{array}$ & Boscoso & Urbano & Pastos & $\begin{array}{c}\text { Pastos } \\
\text { arbolados }\end{array}$ & $\begin{array}{c}\text { Suelo } \\
\text { desnudo }\end{array}$ \\
\hline \multicolumn{8}{|c|}{ Zona alta } \\
\hline Agrícola & NA & NA & NA & NA & NA & NA & NA \\
\hline $\begin{array}{l}\text { Agrícola } \\
\text { arbolado }\end{array}$ & NA & NA & NA & NA & NA & NA & NA \\
\hline Boscoso & NA & NA & 0.9548 & 0 & 0.0233 & 0.0219 & 0 \\
\hline Urbano & NA & NA & 0 & 0.9999 & 0.0001 & 0 & 0 \\
\hline Pastos & NA & NA & 0.0512 & 0.0405 & 0.398 & 0.16 & 0.3503 \\
\hline $\begin{array}{l}\text { Pastos } \\
\text { arbolados }\end{array}$ & NA & NA & 0.1701 & 0.0211 & 0.1774 & 0.5804 & 0.051 \\
\hline $\begin{array}{l}\text { Suelo } \\
\text { desnudo }\end{array}$ & NA & NA & 0.0015 & 0.1371 & 0.0551 & 0.001 & 0.8053 \\
\hline \multicolumn{8}{|c|}{ Zona media } \\
\hline Agrícola & 0.4702 & 0.0918 & 0.0358 & 0.1638 & 0.0638 & 0 & 0.1746 \\
\hline $\begin{array}{l}\text { Agrícola } \\
\text { arbolado }\end{array}$ & 0.3058 & 0.3005 & 0.0066 & 0.0231 & 0.0238 & 0.0044 & 0.3358 \\
\hline Boscoso & 0.022 & 0.0065 & 0.8676 & 0.0196 & 0.0233 & 0.0419 & 0.0191 \\
\hline Urbano & 0 & 0 & 0 & 0.9999 & 0.0001 & 0 & 0 \\
\hline Pastos & 0.0161 & 0.0053 & 0.0812 & 0.0966 & 0.398 & 0.1115 & 0.2913 \\
\hline $\begin{array}{l}\text { Pastos } \\
\text { arbolados }\end{array}$ & 0.0035 & 0.008 & 0.1707 & 0.0232 & 0.1774 & 0.5649 & 0.0523 \\
\hline $\begin{array}{l}\text { Suelo } \\
\text { desnudo }\end{array}$ & 0.0235 & 0.0043 & 0.0178 & 0.4606 & 0.1211 & 0.0188 & 0.3539 \\
\hline \multicolumn{8}{|c|}{ Zona baja } \\
\hline Agrícola & 0.4802 & 0.0618 & 0.0358 & 0.1038 & 0.0638 & 0 & 0.2546 \\
\hline $\begin{array}{l}\text { Agrícola } \\
\text { arbolado }\end{array}$ & 0.2058 & 0.3005 & 0.0066 & 0.2431 & 0.0438 & 0.0044 & 0.1958 \\
\hline Boscoso & 0.012 & 0.0065 & 0.9076 & 0.0096 & 0.0233 & 0.0219 & 0.0191 \\
\hline Urbano & \begin{tabular}{|l|l|}
0 \\
\end{tabular} & 0 & 0 & 0.9999 & 0 & 0 & 0.0001 \\
\hline Pastos & 0.015 & 0.0064 & 0.0812 & 0.2966 & 0.298 & 0.0115 & 0.2913 \\
\hline $\begin{array}{l}\text { Pastos } \\
\text { arbolados }\end{array}$ & 0.002 & 0.008 & 0.4722 & 0.0227 & 0.0779 & 0.3649 & 0.0523 \\
\hline $\begin{array}{l}\text { Suelo } \\
\text { desnudo }\end{array}$ & 0.0225 & 0.0071 & 0.0168 & 0.1195 & 0.0081 & 0.017 & 0.809 \\
\hline
\end{tabular}


Jossy Esteban Calvo-Villalobos, Tania Bermúdez-Rojas, Hannia Vega-Bolaños. Dynamics of Soil Use and Priority Sites for Forest Restoration of the Biological Corridor Tibas River, Costa Rica

\section{Selección de sitios prioritarios para restauración}

Al utilizar la matriz se pudieron delimitar 20 sectores prioritarios, para lo cual se seleccionaron aquellos que presentaron puntajes de $80 \mathrm{o}$ más (Figura 5). Estos sectores corresponden a 168.7 ha, cerca de un $14 \%$ del área total del corredor. El 50 \% de los SP se ubicaron en la zona media, mientras que solo un $11 \%$ en la zona alta. Así bien, los principales tipos de uso de suelo en estos sectores correspondieron a zonas boscosas fragmentadas o degradadas (29\%), cafetales sin sombra $(27 \%)$ y pastos $(20 \%)$.

Figura 5. Sitios prioritarios para restauración de cobertura vegetal y zonas boscosas remanentes en el área destinada al Corredor Biológico Río Tibás
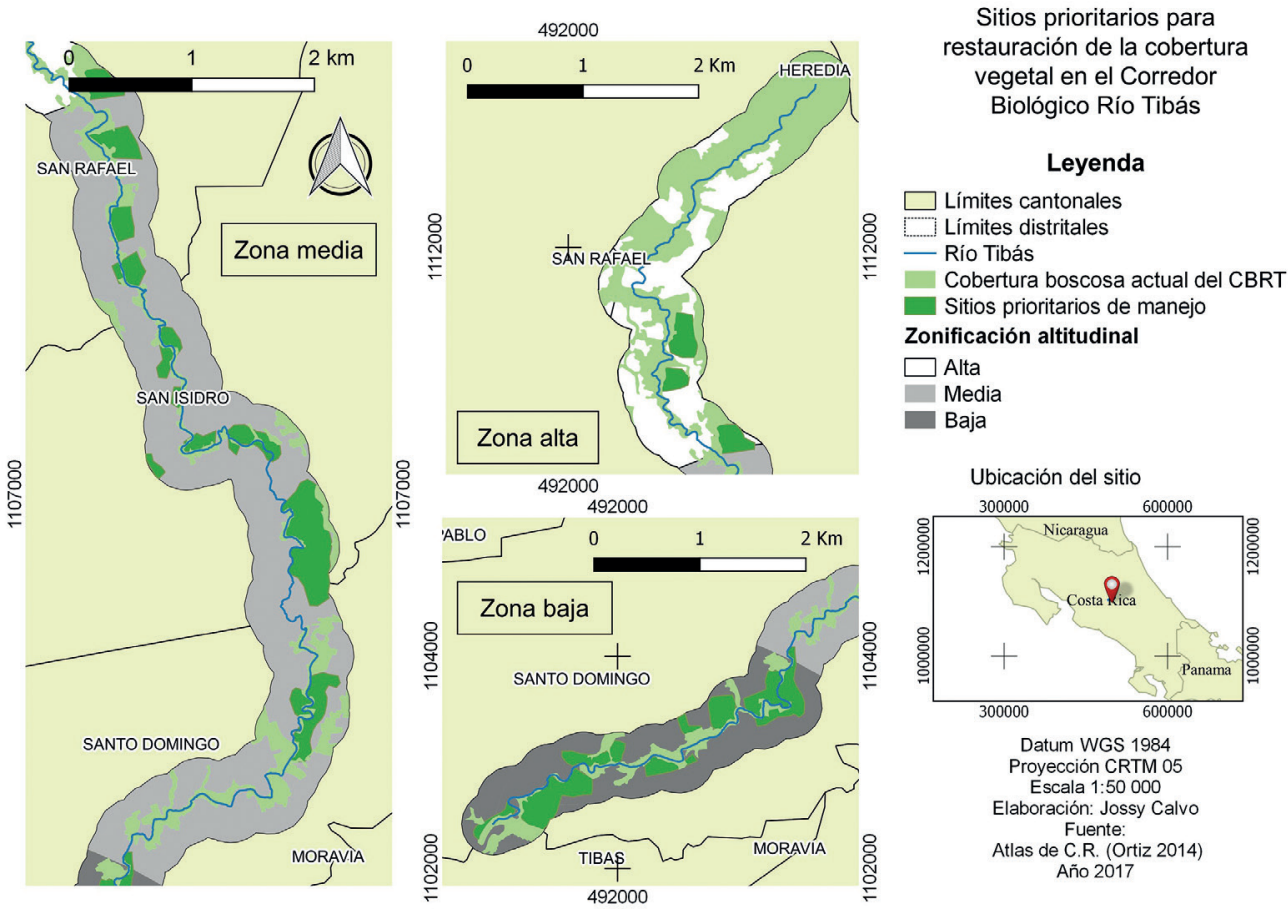

Según los criterios evaluados en la matriz, resalta que el $55 \%$ del área de estudio se encuentra bajo la categoría de "fragilidad ambiental muy alta" (Figura 6), de hecho, un $75 \%$ de los SP se encuentran en zonas con esta condición. Estos terrenos tienen altas restricciones para uso humano y 
Jossy Esteban Calvo-Villalobos, Tania Bermúdez-Rojas, Hannia Vega-Bolaños. Dinámica de uso de suelo y sitios prioritarios para la restauración forestal del Corredor Biológico Río Tibás, Costa Rica

según recomienda la metodología deberían estar restringidos prácticamente a protección forestal. A pesar de ello, actualmente un $18 \%$ de la infraestructura total del CBRT se concentra en estas zonas, así como un $47 \%$ del uso agrícola. Solo un $43 \%$ de las zonas, ambientalmente, muy frágiles se encuentran bajo cobertura boscosa.

\section{Figura 6. Clases y subclases del índice de fragilidad ambiental en el Corredor Biológico Río Tibás, Heredia, Costa Rica.}
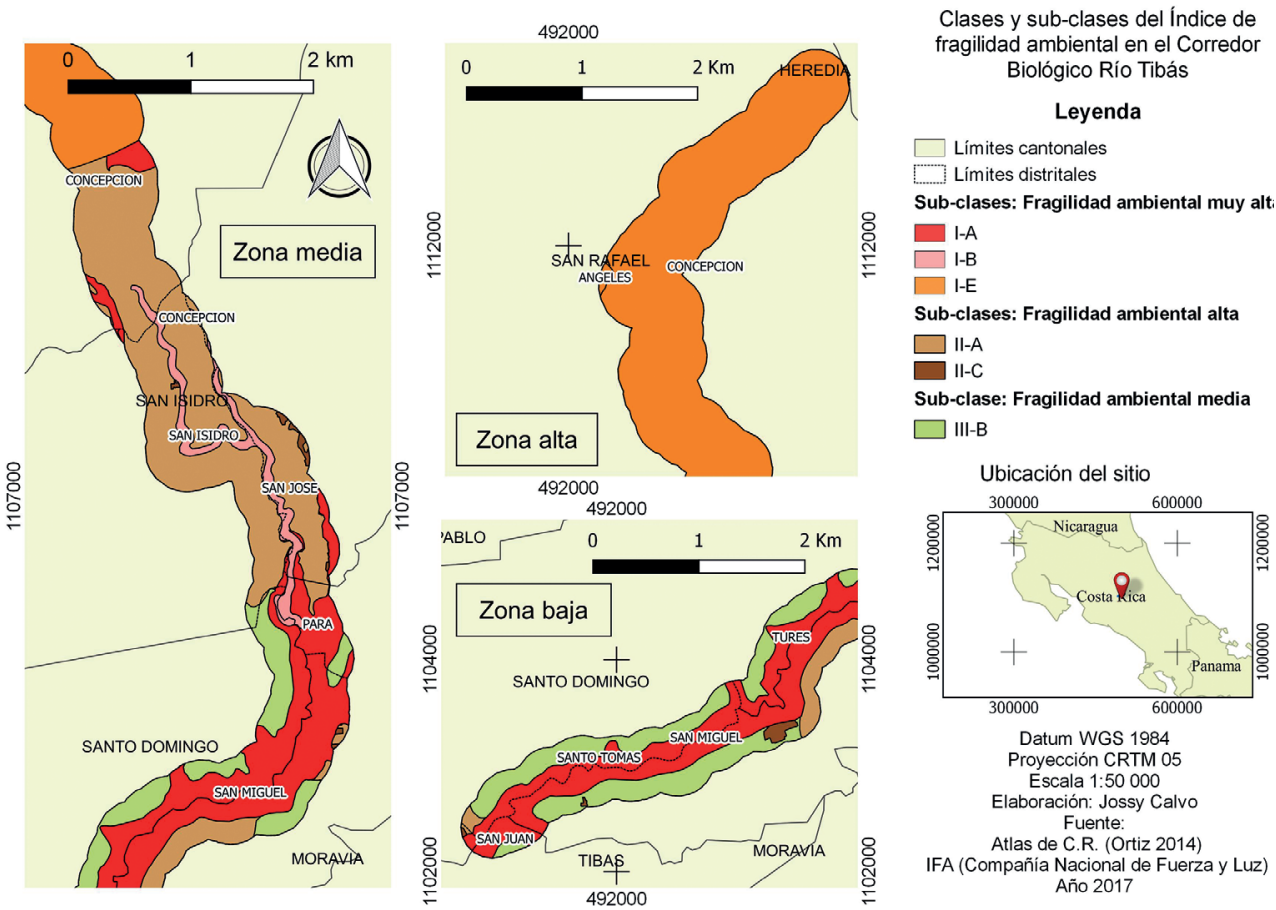

Simbología: I-A = zonas de relieves altos, estabilidad de laderas reducida e importancia en recarga acuífera, recomendadas para cobertura boscosa. I-B = vulnerabilidad alta a media a procesos de erosión, inundación o contaminación, recomendadas para protección o uso agropecuario orgánico. I-E = zonas de alto valor estratégico para recarga acuífera, recomendado maximizar la conservación boscosa. II-A = procesos de erosión y relieve moderado, se recomienda infraestructura de baja densidad $(<20 \%)$. II-C $=$ alta vulnerabilidad a procesos de erosión o deslizamientos, de valor intermedio para recarga acuífera, se recomienda conservación boscosa. II-B = posible desarrollo urbanístico de diverso tipo, entre 60-70\% de densidad.

Por otro lado, el CBRT se caracteriza por poseer en su mayoría pendientes bajas (Figura 7). Casi un $90 \%$ de la zona se encuentra en la 
Jossy Esteban Calvo-Villalobos, Tania Bermúdez-Rojas, Hannia Vega-Bolaños. Dynamics of Soil Use and Priority Sites for Forest Restoration of the Biological Corridor Tibas River, Costa Rica

primera categoría de la matriz “ $\leq 29.9 \%$ de pendiente". Las condiciones más pronunciadas se limitan al estrato alto y parte de la zona baja, más que todo en los márgenes del río donde se encuentran varios cañones con pendientes que oscilan entre los 40 y $60^{\circ}$. A pesar de esta condición, y si bien, la matriz priorizaba zonas planas, un $30 \%$ de los SP tienen pendientes muy altas debido, principalmente, a factores como la fragilidad ambiental de estas zonas, la presencia de zonas protectoras del río y la ausencia de cobertura boscosa en las mismas.

Figura 7. Mapa de pendientes en el área destinada al Corredor Biológico Río Tibás a partir de un modelo de elevación digital y procesamiento de imágenes Raster del sensor ASTER.
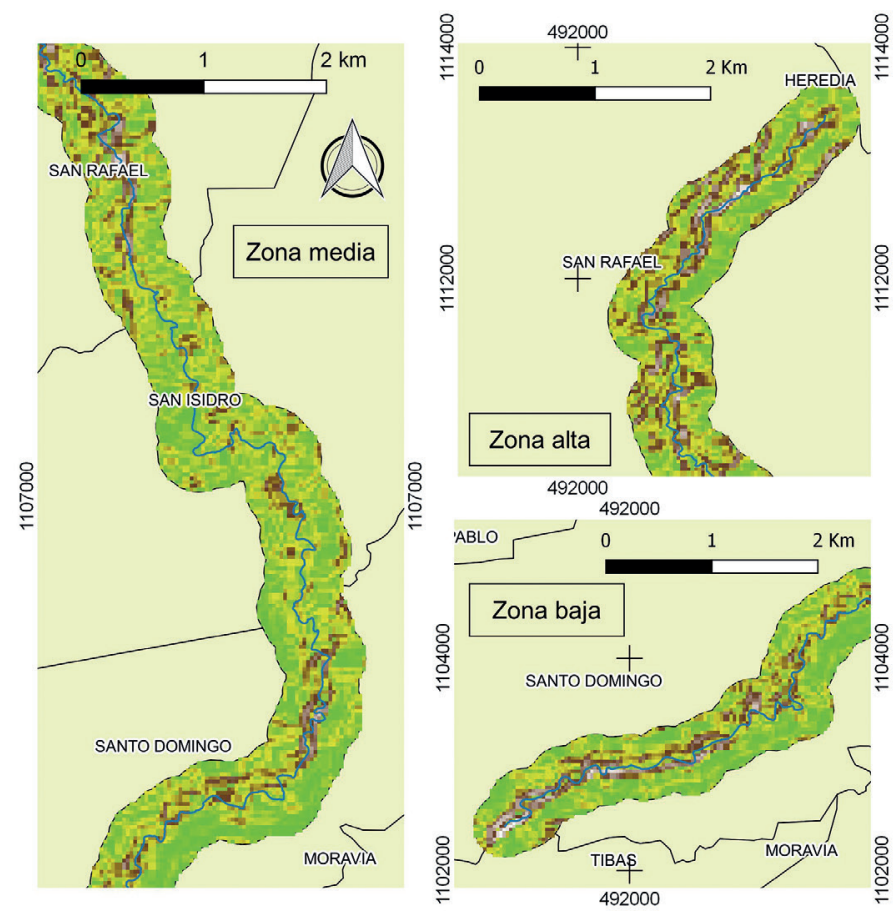
Pendientes en el Corredor Biológico Río Tibás

\section{Leyenda}

$\square$ Límites cantonales — Río Tibás Categoría de pendiente $0-15 \%$

$\square 16-29 \%$

$30-44 \%$

$\square 45-55 \%$ $\square 55-65 \%$

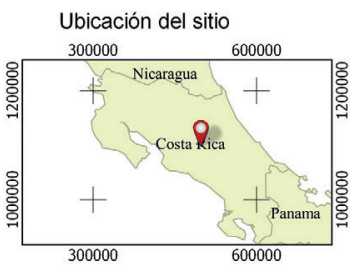

Datum WGS 1984 Proyección CRTM 05 Escala 1:50 000 Elaboración: Jossy Calvo Fuente: Atlas de C R (Ortiz 2014) Imágenes ASTER (Earth Explorer-USGS Año 2017

\section{Diagnóstico social en los sitios definidos como prioritarios}

Los 20 SP se distribuyeron en 73 propiedades. De estas no se pudo contactar a 18 propietarios durante el periodo de la investigación y tres no 
estuvieron anuentes a responder la encuesta. De manera que, se realizaron 52 encuestas en total, correspondientes a 10 de los sitios.

E1 $57 \%$ de los propietarios encuestados mencionaron algún grado de preocupación por problemas ambientales en el río Tibás. En total identificaron 8 problemáticas, de las cuales la más mencionadas fueron la contaminación (31\%), erosión e inestabilidad de taludes $(22 \%)$ y reducción del tamaño del caudal (15\%). Por otro lado, el $96 \%$ de los encuestados (50) tienen una percepción positiva hacia el proyecto del corredor biológico y consideran que es beneficioso para la comunidad, ya sea para conservar el agua $(21 \%)$, la vida silvestre (18\%), disminuir la contaminación del cauce (18\%) o mejorar la imagen de la comunidad (17\%).

De las propiedades donde se aplicaron encuestas el $32 \%(15)$ se encuentran, actualmente, sin ningún uso o aprovechamiento por el propietario(s). En el porcentaje restante la mayoría de usos (al menos en alguna parte de la propiedad) correspondían a cafetales (21\%), huertos familiares $(15 \%)$ y zonas verdes para uso recreativo (13\%). Doce propietarios indicaron que tienen pensado cambiar el uso de suelo de la propiedad a futuro, principalmente para realizar alguna construcción, cambio de cultivo o uso recreativo.

\section{Discusión}

\section{Clasificación de uso de suelo}

El uso de suelo en el área del CBRT es representativo del paisaje general de la región sub-metropolitana en la provincia de Heredia, según lo descrito por Alfaro y Miranda (2006) y Morera et al., (2013). En la parte baja del corredor, el café se ha constituido como la principal actividad económica, mientras se traslapa entre lo rural y urbano. Hacia la periferia Norte predominan tierras dedicadas a la ganadería que coexisten con residenciales de alto ingreso, hasta encontrarse con bosques estatales protegidos.

Cabe resaltar que solo un $17 \%$ de la cobertura del CBRT corresponde a uso urbano. Incluso en el estrato más urbanizado, el de la zona media, este uso representa solo un $28 \%$ del área total. Un porcentaje que se puede considerar bajo en comparación con otros sistemas ribereños de la GAM, que actualmente son foco importante de estudio y manejo, como el río Pirro en la provincia de Heredia o el Torres y María Aguilar en San José, 
Jossy Esteban Calvo-Villalobos, Tania Bermúdez-Rojas, Hannia Vega-Bolaños. Dynamics of Soil Use and Priority Sites for Forest Restoration of the Biological Corridor Tibas River, Costa Rica

donde el uso urbano constituye entre un 50-75 \% de la región (Escalante y Pizarro, 2009; Romero, Piedra, Villalobos, Marín y Núñez, 2013; TrujilloAcosta, Peraza-Estrella, Marina-Hipólito y Boraschi, 2016).

Asimismo, la cobertura boscosa del CBRT es relativamente alta si la comparamos con los valores menores al $12 \%$ (incluso hasta $3 \%$ ) de estos otros sistemas urbanos visiblemente degradados en la GAM (Escalante y Pizarro, 2009; Romero et al., 2013; Trujillo-Acosta et al., 2016). Esta situación podría deberse en parte a las pendientes muy pronunciadas que impiden la invasión de los bosques ribereños, al menos en la zona alta y baja del corredor, así como acciones y políticas de protección en algunos sectores de la zona alta (Herrera, 2010).

\section{Cambio de uso del suelo y tendencias futuras al año 2025}

Si bien, a nivel de paisaje, actualmente, existe una distribución más o menos equitativa entre la cobertura boscosa, agropecuaria y urbana del CBRT, es evidente que hay una tendencia al cambio, particularmente hacia la transformación de cultivos y pastos a uso urbano. En general esta situación concuerda con el panorama socioeconómico actual del GAM y con varios sitios específicos a nivel regional (Morera et al., 2013; Romero et al., 2013).

No obstante, resaltan algunas particularidades en la dinámica del río Tibás. Por ejemplo, el área del CBRT enfrenta un proceso de urbanización y de disminución de uso agrícola casi hasta 3 veces más rápido en comparación con otras regiones, también vulnerables como la microcuenca del río Pirro (Romero et al., 2013).

Por otro lado, según el modelaje la probabilidad de pérdida de cobertura boscosa no sobrepasa el $14 \%$, mientras que a partir de un estudio similar realizado para toda el GAM los usos boscosos proyectan probabilidades de permanecer de tan solo un $23 \%$ a $53 \%$ (Morera et al., 2013). Asimismo, en varias regiones del río María Aguilar (ejemplo Curridabat o La Unión) también se reporta alta vulnerabilidad de coberturas boscosas, que son deforestadas para el implemento de usos agrícolas y residenciales (Solano-Monge, 2017). En este sentido, podría considerarse que al menos en el área del CBRT la cobertura boscosa no es altamente vulnerable al cambio de uso. 


\section{Selección de sitios prioritarios para restauración}

La mayoría de los SP del CBRT se encuentran en la zona baja y media del cauce; las más influenciadas por la urbanización, mientras que en la zona alta la cobertura vegetal favorable, las pendientes mayores y la poca infraestructura de la zona (debido a la relativa temprana urbanización) influyeron en los puntajes menores. Esto contrasta con otras investigaciones que sitúan zonas como San Rafael de Heredia, la Zona Norte de San Isidro y lugares aledaños (estrato alto del CBRT) como muy afectadas recientemente por el crecimiento urbano (ProDus 2004, Aldi, 2013).

Dichas zonas no representaron los mayores puntajes tras la aplicación de la matriz de selección de SP, sin embargo, reflejaron una condición vulnerable tras el análisis de cadenas de Markov. Esto refleja la importancia de la integración de este criterio que no se contemplaba en la propuesta metodológica original (Villalobos, 2013), el cual se implementó como una valoración indirecta del historial del uso de suelo del sitio, que no necesariamente podría corresponder con las hipótesis de otros criterios de la matriz.

Asimismo, en esta metodología se integró la herramienta de análisis multi-criterio del IFA. Un índice con pesos relativamente altos asignados a criterios de aptitud geológica y edafológica, como zonas de recarga acuífera o vulnerabilidad a inundaciones o deslizamientos, entre otros, muy importantes para el enfoque de esta propuesta. De acuerdo con los resultados, el crecimiento urbano en el CBRT en los últimos 11 años se ha dado en un $10 \%$ en zonas de muy alta fragilidad ambiental y un $35 \%$ en zonas de alta fragilidad ambiental, ninguna de las dos aptas para alta densidad urbana. Esta situación refleja que no ha existido un adecuado control por parte de los municipios sobre este crecimiento y resalta la importancia de priorizar el manejo en estos espacios.

\section{Diagnóstico social en los sitios definidos como prioritarios}

El aspecto más positivo del diagnóstico social es que el $94 \%$ de los propietarios están anuentes a que se lleven a cabo iniciativas de restauración en los SP, al menos en las zonas más vulnerables de sus fincas (zonas protectoras del río, con pendientes elevadas). Dicha anuencia la justifican mayormente por el beneficio percibido para la conservación del agua, así como la preocupación por las problemáticas de contaminación (basura, malos olores) y erosión. Situaciones que se han documentado con 
Jossy Esteban Calvo-Villalobos, Tania Bermúdez-Rojas, Hannia Vega-Bolaños. Dynamics of Soil Use and Priority Sites for Forest Restoration of the Biological Corridor Tibas River, Costa Rica

preocupación en la región desde 1998 (Suazo y Ramos 1998, Miranda, Porras y Moreno, 2003). Asimismo, la escasez de agua potable, principalmente, en la época seca, ha sido frecuente en varios sectores del corredor en los últimos años y pudo haber influenciado en el interés mostrado por la conservación de la cobertura vegetal (Rodríguez 2004; Angulo, 2016; Araya, 2016).

También destaca el caso de seis cafetaleros que expusieron interés por cambiar el cultivo debido a que ellos consideran generan pérdidas económicas. No obstante, en cuatro de ellos permanece el interés por conservar el uso agrícola, lo cual puede ser favorable en términos de conservación de cobertura vegetal. Esta situación es común en otras zonas de la GAM, donde otros cultivos como hortalizas y plantas ornamentales han tomado mayor importancia (Wei-Salas y Quirós 2015).

Este uso agropecuario es relevante, ya que está representado en un $41 \%$ de los SP, ya sea a través de huertos familiares o cultivos. Por otro lado, en 14 propiedades mencionaron la importancia del SP para uso recreativo y varios propietarios mencionaron que es frecuente la realización de picnics y paseos familiares por parte de vecinos en distintos puntos del río Tibás. Este valor paisajístico y cultural ha sido mencionado en otros ríos interurbanos y promueve el enfoque de corredores biológicos como espacios de concertación social y uso sostenible de la biodiversidad (Acosta, 2013; Villalobos, 2013).

\section{Implicaciones para manejo}

La posibilidad de manejo en los SP del CBRT se puede considerar favorable en relación con el contexto general encontrado en la GAM. La rehabilitación de ríos urbanos en nuestro país se enfrenta a diversos desafíos, como la ocupación ilegal de tierras y el poco espacio disponible. Por ello, varias propuestas de restauración en estas zonas ribereñas mencionan que es común la falta de interés de los propietarios u ocupantes para impulsar o llevar a cabo iniciativas de manejo (Rojas, 2010; Villalobos, Bermúdez y Romero, 2014)

No obstante, los SP definidos por la matriz en el CBRT no reúnen estas condiciones. Se trata de terrenos relativamente más amplios y en general, la ocupación ilegal de infraestructura en las zonas protectoras del río se concentra solamente en algunos sectores del río. Como se mencionaba 
anteriormente, el relieve pronunciado en diversos puntos del cauce puede contribuir a dificultar este tipo de invasión.

El mayor tipo de uso no conforme en las zonas de retiro del río corresponde a pastos en la zona alta $(10 \%)$ y agrícola en la zona baja (20 $\%)$. Si bien, estos tipos de uso representan un riesgo ambiental y socioeconómico, las probabilidades de manejo son más favorables en relación con el uso urbano y permiten que el propietario en general se muestre más anuente a destinar parte de su propiedad para restauración. Resulta positivo que el área efectiva que se podría restaurar, a partir de lo valorado en la matriz y la disponibilidad de los propietarios, equivaldría a 63.1 ha; un incremento del $10 \%$ de la cobertura boscosa total del CBRT. Esto sin tomar en cuenta las 54 ha restantes de SP, donde no se logró contactar a los propietarios respectivos durante el periodo de esta investigación.

Por otro lado, la permanencia de usos agropecuarios en la región corrobora la importancia del uso de un enfoque ecosistémico que facilite un mejor manejo y conservación en la región, por ejemplo, a partir del incentivo de la implementación de sistemas agroecológicos y silvopastoriles (Shepherd, 2004). Este tipo de intervenciones son necesarias debido, también a la vulnerabilidad que proyectaron estos usos a partir de los modelajes y a comentarios de los mismos propietarios que externaron preocupación por la disminución de su rentabilidad.

Si bien, estrategias de incentivo de Pago por Servicios Ambientales se han constituido como una herramienta importante en la región (Miranda et al., 2003; Montero, 2010), las mismas podrían no ser convenientes o viables en muchos sitios, ya que están conformados por terrenos relativamente muy pequeños (menos de $2 \mathrm{ha}$ ). Por su parte, los tres cantones del corredor poseen alto potencial cultural (ejemplo, por su arraigo agropecuario), así como de paisaje, flora y fauna. De manera que, el desarrollo de proyectos ecoturísticos podría ser una opción altamente viable que vale la pena investigar. Actualmente, es una actividad casi nula dentro del CBRT.

Se debe destacar que el historial y las proyecciones de uso del suelo en el CBRT evidencian una tasa de cambio dinámica y acelerada. De no tomarse medidas de manejo a corto y mediano plazo es muy probable que el paisaje de la región se enfrente a la expansión de zonas impermeables y pérdida de cobertura vegetal proveniente, principalmente, de cafetales y pastos arbolados. Estos dos usos de suelo representan hasta el $49 \%$ de la 
Jossy Esteban Calvo-Villalobos, Tania Bermúdez-Rojas, Hannia Vega-Bolaños. Dynamics of Soil Use and Priority Sites for Forest Restoration of the Biological Corridor Tibas River, Costa Rica

cobertura arbórea de los estratos medio y bajo, por lo que indudablemente son elementos indispensables en la preservación del hábitat y conectividad biológica de la región.

Diversos estudios han resaltado la importancia de estos dos tipos de cobertura. En bosques montanos de Monteverde se encontró que árboles remanentes en pasturas comprenden hasta el $60 \%$ de todos los árboles conocidos en la zona y el $90 \%$ de estos son fuente importante de alimento para las aves silvestres (Harvey et al., 1999). Igualmente, los cultivos de café en Mesoamérica han sido ampliamente reconocidos por el rol crucial que cumplen en el mantenimiento de biodiversidad, conectividad y servicios ecosistémicos, como la polinización y dispersión de semillas (Jha et al., 2014). Por esta razón, la conservación y rehabilitación de estos paisajes, de zonas ribereñas y la intervención de sistemas urbanos, por ejemplo, a través de la arborización de aceras y áreas recreativas, constituyen estrategias clave para la implementación del CBRT (Estrada, 2013).

\section{Conclusiones y recomendaciones}

En el CBRT, el uso rural aún se traslapa con residencias y otras edificaciones de forma casi equitativa. La cobertura boscosa, si bien comprende una proporción importante del paisaje $(27 \%)$ más de la mitad se concentra solo en la zona alta. Asimismo, este sitio se caracteriza por presentar una tasa de cambio de uso bastante acelerada y usos como pastos y cafetales arbolados son los más propensos a desaparecer. Los cuales representan hasta un $49 \%$ de la cobertura arbórea de las zonas bajas del corredor.

La aplicación de la matriz de selección de SP permitió identificar 20 sitios prioritarios de manejo (168.7 ha), ubicados mayormente en las zonas media y baja. De estos, se realizó un diagnóstico social en10 sitios, equivalentes a 114.7 ha y distribuidos en 52 propietarios. El $94 \%$ de los propietarios están anuentes a que se lleve a cabo restauración en algún sector de su propiedad. Indicaron estar principalmente motivados por la conservación del agua, mejorar la imagen del lugar y la disminución de la contaminación actual. De acuerdo con su disponibilidad, esto significaría una restauración de cerca de 63 ha en total y un aumento del $10 \%$ de la cobertura boscosa total del corredor.

Finalmente, es necesario complementar esta investigación con otros estudios. Por ejemplo; 1) análisis de paisaje sobre el impacto que la 
restauración de los SP definidos tendría en elementos fundamentales del corredor como su conectividad. 2) Un diagnóstico social representativo para toda la población del CBRT, con el fin de fortalecer las estrategias de manejo. 3) Investigar el potencial y viabilidad de la implementación de estrategias como senderos urbanos o semiurbanos de interpretación ambiental, agroturismo, refugios de investigación y observación de fauna como alternativas de desarrollo sostenible en el CBRT.

\section{Agradecimientos}

A la Compañía Nacional de Fuerza y Luz por el financiamiento otorgado para esta investigación y en especial a Sergio Feoli y Jorge Araya del Departamento de Recursos Naturales, por todo su apoyo durante el trabajo. A la Escuela de Ciencias Biológicas de la Universidad Nacional de Costa Rica (UNA), por el apoyo logístico y de materiales para el muestreo. A la Escuela de Ciencias Geográficas de la UNA y, particularmente, a Marilyn Romero por la orientación para el diseño metodológico. Finalmente, a Marco Calvo y Ana Hernández por la asistencia para el levantamiento de datos de campo.

\section{Referencias}

Acosta, S. S. (2013). Propuesta de plan para la recuperación de la cubierta vegetal en el cantón de San José, Costa Rica. Geografia em Questão, 6(2), 262-286

Aldi, M. (2013). Plan de desarrollo para una zona de amortiguamiento sostenible entre San Isidro de Heredia y el Parque Nacional Braulio Carrillo. (Tesis de Maestría. Universidad para la Cooperación Internacional), Costa Rica. 102 p.

Alfaro D. y Miranda, P. (2007). Crecimiento poblacional en la subregión metropolitana de Heredia, Costa Rica. Universidad Nacional de Costa Rica, Heredia, Costa Rica.

Andrade, Á. P. (2007). Aplicación del enfoque ecosistémico en Latinoamérica. IUCN. Bogotá, Colombia. pp 7-10.

Angulo, Y. (25 de mayo de 2016). ESPH sigue a la espera de aval de SENARA para solucionar problemas de abastecimiento de agua. El Mundo cr, Noticias de Costa Rica Diario Digital, San José, Costa Rica. Recuperado de http://elmundo.cr/ 
Jossy Esteban Calvo-Villalobos, Tania Bermúdez-Rojas, Hannia Vega-Bolaños. Dynamics of Soil Use and Priority Sites for Forest Restoration of the Biological Corridor Tibas River, Costa Rica

Araya, J. (4 de mayo de 2016). Defensores de acuíferos logran moratoria de desarrollos inmobiliarios. Semanario Universidad, San José, Costa Rica.

Calvo, G. y Mora, J. (2012). Análisis de la calidad de varios cuerpos de agua superficiales en el GAM y la Península de Osa utilizando el índice holandés. Tecnología en Marcha, 25, 37-44

Campos L. y A. Astorga. (2009). La metodología del IFA (Índice de Fragilidad Ambiental) como herramienta de introducción integral de la dimensión ambiental en el ordenamiento del territorio en Costa Rica. Segundo Congreso Internacional Sobre Geología y Minería en la Ordenación del Territorio y en el Desarrollo. Utrillas, España. pp. 153-158.

Escalante-González, X. y Pizarro-Torres, R. (2009). Perfil técnico Corredor Biológico "Río María Aguilar". Municipalidad de San José, Costa Rica.

Estrada, A. (2013). Importancia de los diferentes tipos de cobertura arbórea para la recuperación de la biodiversidad en ambientes urbanos. Ambientico 232-233, 13-19.

Feoli, S. (2013). Corredor Biológico Interurbano del Río Torres y corredores biológicos en general. Ambientico, 232-233, 51-55.

Harvey, C. A., Haber, W. A., Solano, R., y Mejías, F. (1999). Árboles remanentes en potreros de Costa Rica: ¿Herramientas para la conservación? Remnant trees in Costa Rican pastures: tools for conservation?.Agroforestería en las Américas., 6(24), 19-22.

Herrera, M. (2010). Ciencias sociales y gestión ambiental: El caso del desarrollo forestal urbano en Costa Rica. Reflexiones, 89(2).

Jha, S., Bacon, C. M., Philpott, S. M., Ernesto Mendez, V., Läderach, P., y Rice, R. A. (2014). Shade coffee: update on a disappearing refuge for biodiversity. BioScience, 64(5), 416-428.

Leandro, H., Coto, J. y Salgado, V. (2010). Calidad del agua de los ríos de la Microcuenca IV del río Virilla. Uniciencia, 24, 69-74.

Miranda, M., I. Porras y M. Moreno. (2003). El impacto social del esquema de pago de servicios ambientales en Costa Rica: Estudio de campo cuantitativo y análisis de la Cuenca Del Río Virilla. London: International Institute for Environment and Development (IIED). London, United Kingdom. 
Montero, M. (2010). Experiencias y expectativas de la Compañía Nacional de Fuerza y Luz en materia de pago por servicios ambientales. Revista de Ciencias Ambientales, 40(2), 27-33.

Morera, C. M., M. Romero, L. Sandoval y M. Alfaro. (2013). Transformaciones y tendencias futuras en el paisaje periurbano de la región Gran Área Metropolitana (GAM) entre 1986 y el 2005. Geografía, paisaje y conservación. Eds. Morera C., M. Romero y L. Sandoval. Universidad Nacional de Costa Rica, Heredia, Costa Rica.

Murty, P. S., y Tiwari, H. (2015). Accuracy Assessment of Land Use Classification-A Case Study of Ken Basin. Journal of Civil Engineering and Architecture Research, 2(12), 1199-1206.

Ortiz, E. (2014). Atlas Digital de Costa Rica 2008 (CD). Instituto Tecnológico de Costa Rica. Cartago, Costa Rica.

Paegelow, M., M. Olmedo y J. Toribio. (2003). Cadenas de Markov, evaluación multicriterio y evaluación multiobjetivo para la modelización prospectiva del paisaje. GeoFocus, 3, 22-44.

ProDUS (Programa de Investigación de Desarrollo Urbano Sostenible). 2004. Diagnóstico Biofísico del proyecto: Adaptación del Sector Hídrico al Cambio Climático. Escuela de Ingeniería Civil, Universidad de Costa Rica. San José, Costa Rica. pp. 19-53.

QGIS Development Team, (2009). QGIS Geographic Information System. Open Source Geospatial Foundation. URL http://qgis.osgeo.org.

Ramírez, R. (2007). Recarga potencial del acuifero Colima y Barba, Valle Central, Costa Rica. San José, Costa Rica. Servicio Nacional de Aguas Subterráneas, Riego y Avenamiento. Periodo 2007. 41 p.

Rodríguez, F. (6 de diciembre de 2004). Problemas con agua también en otros cantones de Heredia. La Nación, San José, Costa Rica.

Rojas, C. R. (2010). Propuesta para restauración de la zona de los diques, reserva nacional río Reventado, Cartago, Costa Rica. (Tesis de licenciatura. Instituto Tecnológico de Costa Rica), Cartago, Costa Rica.

Romero-Vargas, M., Piedra-Castro, L. Villalobos-Chacón, R., MarínMonge, R. y Núñez-Obando, F. (2013). Evaluación ecológica rápida de un ecosistema urbano: el caso de la microcuenca del Río Pirro, Heredia, Costa Rica. Revista Geográfica de América Central, 47, 41-70. 
Jossy Esteban Calvo-Villalobos, Tania Bermúdez-Rojas, Hannia Vega-Bolaños. Dynamics of Soil Use and

Rosenfield, G. H., y Fitzpatrick-Lins, K. (1986). A coefficient of agreement as a measure of thematic classification accuracy. Photogrammetric engineering and remote sensing, 52(2), 223-227.

Sanderson, J., K. Alger, G. da Fonseca, C. Galindo-Leal, V. Inchausty y K. Morrison. (2003). Biodiversity conservation corridors: planning, implementing, and monitoring sustainable landscapes. Conservation International, Washington, D.C. United States of America. pp 10-11. Shepherd G., (2004). The Ecosystem Approach: Five Steps to Implementation. IUCN, Gland, Switzerland and UK Cambridge, Vi. 30 p.

Solano-Monge, F. (2017). Propuesta de zonificación ambiental del corredor biológico interurbano río María Aguilar, Costa Rica. Revista de Ciencias Ambientales, 51(1), 33-50.

Suazo, A. y Ramos, J. (1998). Perfil: plan de Mejoramiento Ambiental de la Parte Alta de la Cuenca del Río Virilla (PLAMA Virilla). Compañía Nacional de Fuerza y Luz. San José Costa Rica.

Trujillo-Acosta, A., Peraza-Estrella, M. J., Marina-Hipólito, J. G., y Boraschi, S. F. (2016). Evaluación del Corredor Interurbano Río Torres, Costa Rica. Revista Forestal Mesoamericana Kurú, 14(34), 53-62.

Villalobos, R. (2013). Rehabilitación forestal de la zona de protección de la microcuenca del río Pirro, Heredia, Costa Rica. (Tesis de Licenciatura. Escuela de Ciencias Ambientales, Universidad Nacional de Costa Rica). Heredia, Costa Rica. 78 p.

Villalobos, R., Bermúdez, T., y Romero, M. (2013). Percepción de la rehabilitación forestal de la zona de protección del río Pirro tienen sus vecinos. Revista de Ciencias Ambientales, 46(2), 75-83.

Wei-Salas, S., A. y Quirós, A. (2015). Caracterización del uso del suelo en las principales áreas agrícolas de la Gran Área Metropolitana (GAM) de Costa Rica. Agronomía costarricense: Revista de ciencias agrícolas, 39(1), 149-160. 